\title{
Application of a Promoter Isolated from Chlorella Virus in Chlorella Transformation System
}

\author{
Hyoun-Hyang Park and Tae-Jin Choi* \\ Department of Microbiology, Pukyong National University, Busan 608-737, Korea \\ (Received on April 1, 2004; Accepted on May 16, 2004)
}

Chlorella is a eukaryotic microalgae which shares metabolic pathways with higher plants. These characteristics make chlorella a potential candidate for eukaryotic overexpression systems. Recently, a foreign flounder growth hormone gene was stably introduced and expressed in transformed Chlorella ellipsoidea by using a modified plant transformation vector that contains cauliflower mosaic virus (CaMV) $35 \mathrm{~S}$ promoter and the phleomycin resistant $S h$ ble gene as a selection marker. In this study, this same vector was modified by incorporating a promoter and a 3' UTR region of the $33 \mathrm{kDa}$ peptide gene from a chlorella virus that was isolated in our laboratory. The $33 k D a$ gene promoter was used to replace the $35 \mathrm{~S}$ promoter and the 3' UTR was introduced to separate the target gene and downstream Sh ble gene. Three different chlorella transformation vectors containing human erythropoietin (EPO) gene were constructed. The mp335EPO vector consists of a promoter from the $33 k D a$ peptide gene, whereas the mp3353EPO vector contains the same promoter from the $33 k D a$ peptide gene and its $3^{\prime}$ UTR. The mp35S33pEPO vector contains the $35 \mathrm{~S}$ promoter and the 3' UTR from the $33 k D a$ peptide gene. There was no significant difference in the expression levels of EPO protein in chlorella cells transformed with either of three of the transformation vectors. These data indicate that the promoters from the chlorella virus are comparable to the most common CaMV $35 S$ promoter. Furthermore, these data suggest that other promoters from this virus can be used in future construction of chlorella transformation system for higher expression of target proteins.

Keywords : Chlorella, transformation, chlorella virus, promoter, EPO

Chlorella is a unicellular eukaryotic green microalgae which has been widely used for live food in aquaculture and for health food industry. This organism can be cultured inexpensively because it requires only limited amount of

\footnotetext{
*Corresponding author.

Phone) +82-51-620-6367, FAX) +82-51-611-6358

E-mail) choitj@pknu.ac.kr
}

minerals and sunlight, and it is readily cultured to a large scale in a contained pool environment. Furthermore, it also grows relatively fast and divides 2-9 times per day depending upon the light intensity and temperature (Sorokin and Krauss, 1958). These advantages make chlorella an attractive candidate for the large-scale production of recombinant proteins in a eukaryotic expression systems.

Despite these numerous advantages, the use of chlorella for the expression of foreign proteins has been limited due to several problems in this system. For example, Jarvis and Brown (1991) reported a transient expression of a firefly luciferase gene in transformed Chlorella ellipsoidea but the protein was expressed only 52 hours. Recently, the flounder growth hormone $(f G H)$ gene was stably introduced and expressed in transformed $C$. ellipsoidea by utilizing the modified plant transformation vector (Kim et al, 2002). This vector was constructed with the cauliflower mosaic virus (CaMV) $35 \mathrm{~S}$ promoter for the expression of foreign genes and the phleomycin resistance $S h$ ble gene was used as a selection marker.

Even though it has been reported that CaMV $35 \mathrm{~S}$ promoter works in microalgae including Chlamydomonas (Dunahay, 1993; Hasnain et al., 1985), the efficiency of this promoter has not been compared with other promoters that function in chlorella. Recently, the entire genome of a chlorella virus, PBCV-1, has been cloned and sequenced (Gerald et al., 1996). This virus encodes many useful genes including restriction/modification enzymes, topoisomerase, chitinase and hyaluronam synthase (Zhang et al., 1998; Xia et al., 1986; Lavrukhin et al., 2000; Sun et al., 1999; Graves et al., 1999). In addition, several putative promoter sequences have been identified in the PBCV-1 genome characterized by high $\mathrm{A}+\mathrm{T}$ content up to $80 \%$ (Anne et al., 1990). One sequence that is of interest is the promoter for the $33 \mathrm{kDa}$ peptide gene $(33 \mathrm{kDa})$. The biological function of $33 \mathrm{kDa}$ has not been determined, but it is the most abundant protein in the in vitro translation of mRNA isolated from PBCV-1 infected cell (Graves and Meints, 1992). This protein was detected at the beginning at $20 \mathrm{~min}$ post-infection of $\mathrm{PBCV}$ 1 virus. Because this promoter is very strong and since it can be transcribed by host RNA polymerase early in the infection cycle, these were important factors to consider in 
the search for promoters for the chlorella expression system.

The other factor considered in the vector construction is the termination of transcription. Schuster et al. (1990) reported that the TTTTTNT transcriptional termination motif found from vaccinia virus (Yuen and Moss, 1987) was also present downstream from all 5 major PBCV-1 ORFs. It is possible that, like vaccinia virus, it signals the termination of transcription for PBCV-1 (Schuster et al., 1990).

The combinational effect of $33 k D a$ promoter and its $3 '$ UTR from chlorella virus isolated in our laboratory (Cho et al., 2002) was analyzed using the human erythropoietin (EPO) gene and the results were compared to develop a transformation vector for efficient and stable expression of foreign proteins using transformed chlorella.

\section{Materials and Methods}

Preparation of $33 \mathrm{kDa}$ peptide promoter, 3 ' UTR from chlorella virus, and EPO gene. Twenty three chlorella virus isolates have been isolated from fresh water samples collected from 10 cites in Korea (Cho et al., 2002). The 33kDa gene promoter and 3' UTR were amplified by PCR from 6 isolates, YK-1, YK-2, SS-1, HS, $\mathrm{KH}$ and BO. PCR amplification was conducted with virus particles without purification of genomic DNA. Primers for the 33kDa promoters (335N, 5'-GAGAAGCTTTTGAGACCTGT-3' and 335C, 5'-GGCGAATTCGGATCCATGGTATGTTCTTTTCTT-3') and the 3' UTR (333N, 5'-GGCGAATTCCTCGAGATAACTGATTGAATTGAT-3' and 333C, 5-TCAGTCGACAGAACATTTCCGTTGGCG-3') were designed based on the published sequence of PBCV-1. Purified virus particles were heated at $98^{\circ} \mathrm{C}$ for $10 \mathrm{~min}$ and then $3 \mu \mathrm{L}$ of the denatured virus was used for PCR. The PCR reaction conditions were: 35 cycles of $30 \mathrm{sec}$ denaturation at $95^{\circ} \mathrm{C}, 30 \mathrm{sec}$ annealing at $55^{\circ} \mathrm{C}, 30 \mathrm{sec}$ extension at $72^{\circ} \mathrm{C}$ followed by $5 \mathrm{~min}$ extension at $72^{\circ} \mathrm{C}$. The $33 \mathrm{kDa}$ peptide promoter amplified by PCR was digested with HindIII and $B a m \mathrm{H}$ $I$ and cloned into pBluescript II SK+ vector. The PCR products for the 3' UTR were precipitated with ethanol and cloned into the pGEM T-easy vector (Promega. USA). A plasmid containing the human EPO gene was kindly provided by Dr. Hyo-Jeong Hong at the Korea Research Institute Bioscience and Biotechnology. The EPO gene was amplified with PCR primers designed for a vector that each containing 5 ' partial region of the CaMV 35 S promoter and the $33 \mathrm{kDa}$ gene peptide promoter (Table 1).

Vector construction containing $33 k D a$ gene promoter, EPO gene and 3' UTR. In order to compare the effect of the $33 \mathrm{kDa}$ gene promoter and the $3^{\prime}$ UTR on the expression of the EPO gene in transformed chlorella, three different expression vectors were constructed as follows using pCTV vector described by Kim et al. (2002). The mp335EPO vector contains the $33 k D a$ gene promoter and EPO gene. The mp3353EPO vector contains the $33 \mathrm{kDa}$ gene promoter, the EPO gene, and the 3 'UTR. The $33 k D a$ gene promoter was digested with HindIII and BamHI, and cloned into the pCTV to replace the CaMV $35 \mathrm{~S}$ promoter and resulted in mpCTV335 vector. The EPO gene was digested with $\mathrm{BamHI}$ and XhoI, and then cloned into the mpCTV335, resulted in mp335EPO vector. The $33 k D a$ gene 3 'UTR was digested with Xhol and SalI, cloned into the mp335EPO and resulted in mp3353EPO vector. The third vector, mp35S33pEPO that has the CaMV $35 S$ promoter, EPO and the $33 k D a$ gene 3 ' UTR was constructed by replacing the fGH gene in pCTV with EPO gene, followed by cloning of the $33 \mathrm{kDa}$ gene 3' UTR downstream of the EPO gene using the XhoI and Sall sites (Fig. 1).

Chlorella transformation. Chlorella ellipsoidea (Strain No. KMCC C-20) was transformed with the methods described by Kim et al. (2002). Exponentially growing chlorella cells were harvested by centrifuging for $5 \mathrm{~min}$ at $3,000 \times \mathrm{g}$. Cells were washed once with $25 \mathrm{mM}$ phosphate buffer ( $\mathrm{pH} \mathrm{6.0)}$ and protoplasts were prepared by using an enzyme mixture as previously described (Kim et al, 2002). Protoplasts in $0.6 \mathrm{M}$ sorbitol/mannitol with $0.05 \mathrm{M} \mathrm{CaCl}_{2}\left(0.4 \mathrm{~mL}, 10^{7}-10^{8}\right.$ cells $)$ were mixed with $5 \mu \mathrm{g}$ of vector DNA and $25 \mu \mathrm{g}$ calf thymus DNA as carrier. After 15 min incubation at room temperature, $200 \mu \mathrm{L}$ of PNC $\left(0.8 \mathrm{M} \mathrm{NaCl}, 0.05 \mathrm{M} \mathrm{CaCl}_{2}, 40 \%\right.$ PEG 4000$)$ was added with gentle mixing. After $30 \mathrm{~min}$ incubation at room temperature,

\section{A. $\mathrm{mp335EPO}$}

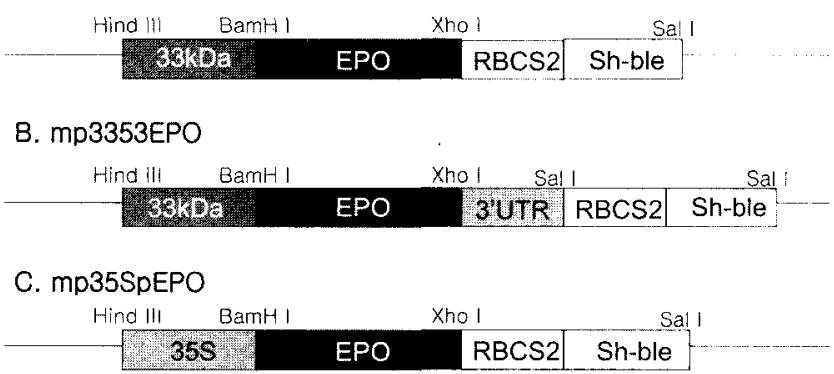

Fig. 1. Structure of chlorella transformation vectors constructed in this study.

Table 1. Oligonucleotide primers used for EPO gene amplification.

\begin{tabular}{llcl}
\hline \hline Primer & Sequence & Remarks & Description \\
\hline EPON & 5'-AGATGGATCCGCACGAATGTCCTGC -3' & Bam $\mathrm{HI}$ & forward, connected to the 33kDa gene promoter \\
pEPON & 5'-CGGGATCCGGTCAGTCCCTTATGGGGGTGCACGAA -3' & BamHI & forward, connected to the CaMV 35S promoter \\
EPOC & 5'-CCAGCTCGAGACACCTGGTCATCTG -3' & XhoI & EPO gene reverse primer \\
EPOISN & 5-ATCTGTGACAGCCGAGTCCT-3 & - & forward primer for probe \\
EPOISC & 5'-GTGTCAGCAGTGATTGTTCG-3' & - & reverse primer for probe \\
\hline
\end{tabular}


$0.6 \mathrm{~mL}$ of $\mathrm{f} / 2$ medium containing $0.6 \mathrm{M}$ sorbitol/mannitol, $1 \%$ yeast extract and $1 \%$ glucose was added and the cells were incubated at $25^{\circ} \mathrm{C}$ for $12 \mathrm{~h}$ in dark for cell wall regeneration. The transformed cells were transferred to fresh $\mathrm{f} / 2$ containing $1 \mu \mathrm{g} / \mathrm{mL}$ of phleomycin and cultured under 3000 lux fluorescent lamp at $25^{\circ} \mathrm{C}$ with $18: 6 \mathrm{~h}$ light:dark cycle. After 8 days of culture, cells were transferred to fresh medium containing the same phleomycin concentration.

Southern blot analysis. Genomic DNA from chlorella was isolated as described by Dawson et al. (1997). Three milliliters of cells grown to approximately $1 \times 10^{8}$ cells $/ \mathrm{mL}$ were pelleted and resuspended in $500 \mu \mathrm{L}$ of CTAB buffer [ $54 \mathrm{mM}$ hexadecyltrimethyl ammonium bromide (CTAB), $0.25 \mathrm{mM}$ Tris (pH 8.0), 1.4 $\mathrm{M} \mathrm{NaCl}, 10 \mathrm{mM}$ EDTA, and $2 \% \beta$-mercaptoethanol]. The mixture was incubated at $65^{\circ} \mathrm{C}$ for $1 \mathrm{~h}$ and then extracted with equal volume of phenol/chloroform. The extract was centrifuged at $3,000 \times \mathrm{g}$ for $5 \mathrm{~min}$ and the aqueous phase was transferred to a new tube. Extraction was repeated until aqueous layer was no longer cloudy. The DNA was precipitated with 0.7 volume of $100 \%$ ethanol and pelleted for $15 \mathrm{~min}$ at $1,7000 \times \mathrm{g}$. The pellet was washed with $70 \%$ ethanol and resuspended in $30 \mu \mathrm{L}$ TE buffer. The EPO gene was amplified from the purified genomic DNA using methods described above and with primers listed in Table 1. Templates for EPO gene probe were prepared by PCR with the EPOISN and EPOISC primers located in EPO gene ORF (Table 1). The probe was synthesized using the digoxigenin (DIG) oligonucleotide 3'-end labeling kit (Boehringer Mannheim, Germany), and the quality of this probe was immunologically determined with the DIG-DNA Detection kit (Boehringer Mannheim). Southern blot analysis was performed as previously described (Kim et al., 2002).

ELISA. EPO protein expressed in transformed chlorella was quantified by Enzyme-Linked Immunosorbent Assay (ELISA). Ten milliliters of transformed chlorella $\left(1 \times 10^{8}\right.$ cells $\left./ \mathrm{mL}\right)$ were centrifuged for $10 \mathrm{~min}$ at $2,000 \times \mathrm{g}$. The pellet was immersed in liquid nitrogen, crushed with a homogenator (Wheaton) and centrifuged for $1 \mathrm{~min}$ at $13,000 \times \mathrm{g}$. The supernatant was diluted $1: 2,1: 5,1: 10$, and $1: 100$ in $100 \mu \mathrm{L}$ of phosphate-buffered saline buffer (PBS. A 96 well assay plate (Coming, USA) was coated with $100 \mu \mathrm{L}$ sample solution at $37^{\circ} \mathrm{C}$ for $2 \mathrm{~h}$. The plate was washed three times with PBS containing $0.08 \%$ Tween-20 (PBST) and blocking buffer (PBS-T plus $2 \%$ bovine serum albumin) was added to each well. The plate was incubated for $30 \mathrm{~min}$ at $37^{\circ} \mathrm{C}$. After blocking buffer was removed, the antibody which was raised against EPO from rabbit (Santa Cruze, diluted 1:1,000 in PBS-T) was added and the plate was incubated at $37^{\circ} \mathrm{C}$ for $2 \mathrm{~h}$, washed, and blocked as described above. Alkaline phosphatase conjugated anti-rabbit IgG serum diluted 1:30,000 in PBS-T was added to each well and incubated at $37^{\circ} \mathrm{C}$ for $2 \mathrm{~h}$. The plate was washed three times with PBS-T, followed by one wash with distilled water. Substrate (10 mg p-nitrophenyl phosphate dissolved in $10 \mathrm{~mL}$ of Diethanolamine buffer, $\mathrm{pH}$ 9.8) was added to each well and the plate was incubated at room temperature for $30 \mathrm{~min}$. The reaction was stopped with the addition of $100 \mu \mathrm{L}$ of $0.1 \mathrm{M}$ EDTA and the optical density $\left(\mathrm{OD}_{405}\right)$ was measured at 405 $\mathrm{nm}$ with UV $900 \mathrm{C}$ (Bio-Tek instruments Inc.).

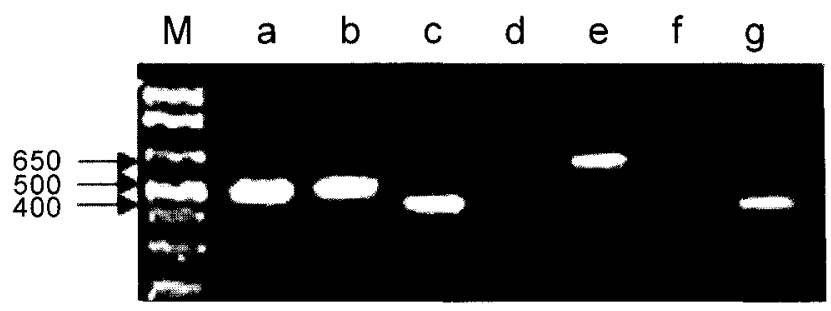

Fig. 2. PCR amplification of the $33 k D a$ gene promoter from chlorella virus isolated in Korea. All of the PCR products were sequenced and the PCR product from YK-1 isolate was used for the construction of modified Chlorella transformation vector. Lane M, $1 \mathrm{~kb}$ plus DNA size marker; lane a, YK-1; lane b, YK-2; lane c, KH; lane d, SS-2; lane e, BO; lane f, HS; lane g, PBCV-1.

\section{Results}

Isolation of chlorella virus $33 k D a$ gene promoter. PCR products were detected from YK-1, YK-2, KH and BO from 6 chlorella virus isolates used for the PCR amplification of the $33 k D a$ gene promoter (Fig. 2). However, the size of PCR products was variable. PCR product size was approximately $410 \mathrm{bp}$ in $\mathrm{YK}-1,480 \mathrm{bp}$ in YK-2, 400bp in $\mathrm{KH}$ and 580bp in BO. There was no PCR product detected from the isolates SS-2 and HS (Fig. 2). Sequencing of the $33 \mathrm{kDa}$ gene promoter of YK-1 showed an insert of $405 \mathrm{bp}$. This sequence was compared with the sequence of the $33 \mathrm{kDa}$ gene promoter of the prototype chlorella virus strain, PBCV-1, and two viruses showed $96 \%$ nucleotide sequence homology in this region (Fig. 3).

Cloning and Sequencing of the 3'UTR of the 33kDa gene. The $3^{\prime}$ UTR of the $33 \mathrm{kDa}$ gene was amplified from 6 chlorella virus isolates. Although PCR products were detected from all of the isolates, the product size was variable. Specifically, amplified products were approximately $600 \mathrm{bp}$ in SS-1, 490bp in HS, 500bp in YK-1, 520bp in YK2, 600bp in KH and 490bp in BO (Fig. 4). Sequence analysis of the $3^{\prime}$ UTR of the $33 \mathrm{kDa}$ gene from YK-1 and the counter part of PBCV-1 showed 88\% nucleotide sequence homology. The sequence TTTTTTT, which is known to be important in transcription termination of vaccinia virus early genes (Yuen and Moss, 1987), was not found in the 3' UTR of the $33 \mathrm{kDa}$ gene of YK-1 isolate. Transformation of chlorella cells. Chlorella protoplasts were prepared and transformed with the three vectors as described. Cell walls were regenerated from protoplasts by incubating transformed protoplasts overnight in the presence of an osmotic stabilizer. Transformed cells were then selected by adding phleomycin at the final concentration of $1 \mathrm{ug} / \mathrm{mL}$. The initial cell number was $3.0 \times 10^{7}$ cells in 40 $\mathrm{mL}$ media and cell growth was detected after 7 days incubation. The cell count reached $10^{8}$ cells $/ \mathrm{mL}$ in 10 days. The cells were transferred into fresh $\mathrm{f} / 2$ medium containing 
PBCV-1 aagct $t \mathrm{t}$ tgagacctgt $t \mathrm{t}$ tat at aact tcggtgtggtaggaaaa YK-1 aagct t tgagacctgt t tatat aact tcggtgtggtaggaaaa cggggt ccagt acccggt tgggt gt tgccggcgacgat agcatccgtggt $t \mathrm{t} t$ cgggg t ccagt acccggt tgggt gt tgccggcgacgat agca t cagtggt $t \mathrm{t} t$

gt tggt tct tatct tgat tacct tgat caaaat $t$ tacgagag tatcaccactg gt tggt tct tat ct tgat t acct tgatcaaaat t tacgagagtatcaccactg

gaaag tgca tgatgtgtgggacaa tacat aaaaatgacaaatgacaaat aaat gaaagt gca tgg tatgtgggg tgaaaca taaaa-tgacaaatgacaaat aaat

gacaaat aaa gacaacca tcat at cgacaagaaaaagcat t taagcaactgt gacaa--------ccgtcatat cgacaagaaaaagcat t taagcaactgt

$t t t$ cacact aaac tcat ct tcctcct tcgggac accatctgaacaact actg $t \mathrm{t}$ tcacact $\underline{\text { aaac }}$ tcat ct $t$ cctcct $t$ cgggac taccat ct gaacaact actg aacaaacaaacaaacaaacaaacaaacaaacaaacaaacaaacaaacaaacgc aacaaacaaacaaacaaacaaacaaacaaacaaacaaa---------c gc

tctccgt aaacaaacct caa taaccct caaacaaat tccc-aaagaaaagaac tctccgt aaacaaacct caat aaccct caaacaaact ccccaaagaaaagaac

ata--atgg

ataccatgg

Fig. 3. Comparison of the $33 k D a$ promoter sequence of PBCV-1 and $\mathrm{YK}-1$. The repeated AAAC sequences are underlined and the gaps in the YK-1 isolate are indicated with dashes.

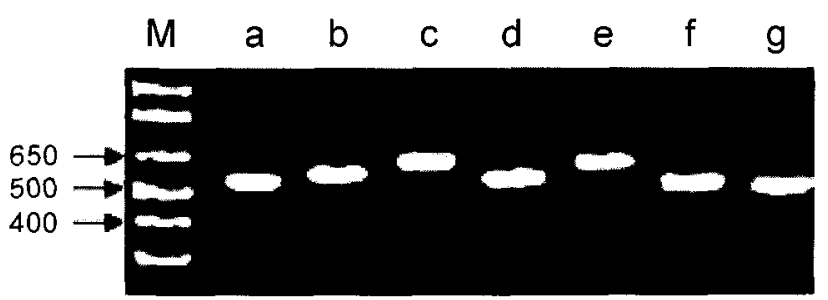

Fig. 4. PCR application of the $3^{\prime}$ UTR of the $33 k D a$ gene from chlorella virus isolated in Korea. All of the PCR products were sequenced and the PCR product from YK-1 isolate was used for the construction of transformation vector. Lane $\mathrm{M}, 1 \mathrm{~kb}$ plus DNA ladder size marker (Gibco BRL); lane a, amplified PBCV-1; lane b, amplified YK-1; lane c, amplified YK-2; lane d, amplified KH; lane e, amplified SS-2; lane f, amplified BO; lane $\mathrm{g}$, amplified $\mathrm{HS}$.

$1 \mathrm{ug} / \mathrm{mL}$ phleomycin at a 10 day interval. There was no growth of non-transformed cell in the presence of $1 \mathrm{ug} / \mathrm{mL}$ phleomycin and green color disappeared after 7 days.

Detection of the EPO gene from transformed chlorella. The stable integration of introduced DNA into genomic DNA is a prerequisite for usage of this transformed chlorella system as a bioreactor. The integration of introduced DNA into chlorella genomic DNA was tested by PCR using purified genomic DNA. PCR products of expected size were detected from the chlorella cells transformed with the mp335EPO, mp3353EPO and mp35S33pEPO vectors but not from the non-transformed chlorella cells (Fig. 5A). The PCR product was further confirmed by Southern blot analysis with EPO gene probe, which showed specific hybridization of the probe to PCR products from transform-

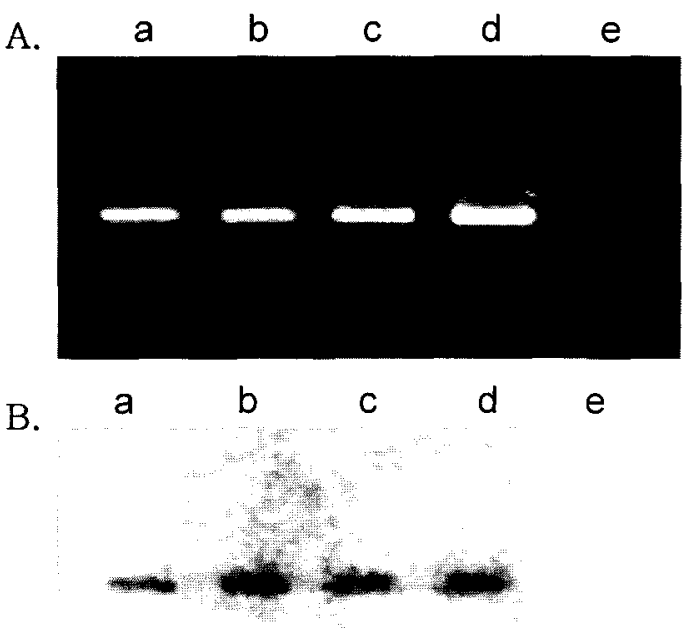

Fig. 5. PCR amplification of EPO gene from genomic DNA of chlorella cells transformed with various transformation vectors (A) and southern blot analysis with EPO gene probe (B). Lane a, positive control; lane b, mp35S33pEPO; lane c, mp335EPO; lane d, mp3353EPO; lane e, wild type.

ed cells (Fig. 5B).

Expression of erythropoietin protein in chlorella. The expression of the introduced EPO gene was tested by ELISA analysis. Total proteins from transformed and nontransformed chlorella were analyzed by using the antibody specific for the EPO protein. EPO protein was detected only from transformed chlorella and was not found in the non-transformed negative control. However, it is important to note that EPO expression levels from the three constructs were not significantly different (Fig. 6).

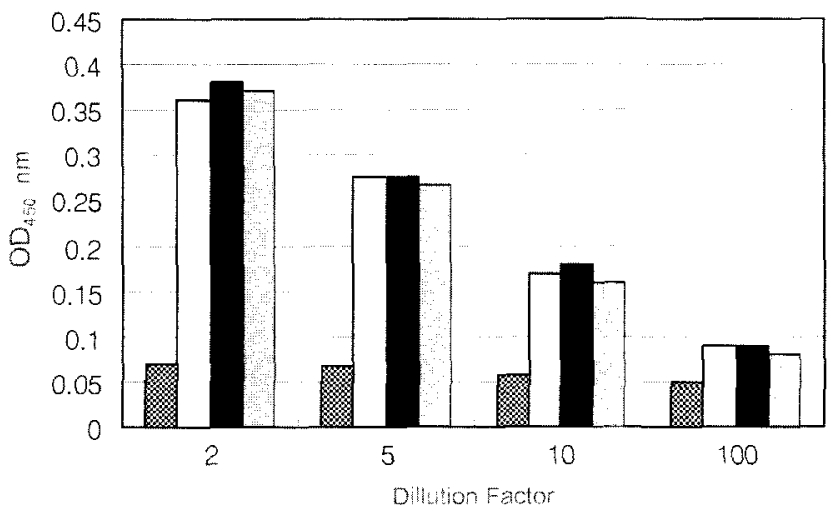

Fig. 6. Detection of the expressed EPO protein from transformed Chlorella and non-transformed Chlorella. Check bar, nontransformed Chlorella; white bar, Chlorella transformed with mp3353EPO vector; black bar, Chlorella transformed with mp335EPO vector; gray bar, Chlorella transformed with mp35S33pEPO vector. 


\section{Discussion}

Although chlorella has many attractive characteristics that are required for a good heterologous expression system, development of this organism as an expression system has been hampered by the lack of an appropriate transformation vector. Recently, the achievement of chlorella transformation and the expression of a foreign gene using the flounder growth hormone gene suggested that foreign genes can be stably integrated and expressed in transformed chlorella (Kim et al., 2002). Additionally, it was proved that the expressed protein has biological activity and promoted the growth of juvenile flounder when the protein was indirectly provided to small fish that fed on zooplankton. Zooplankton provided the indirect source of chlorella since they consumed the transformed chlorella.

Although the CaMV 35S promoter has been used in the transformation and proven to function in microalgae (Amitava et al., 1994; Eric et al., 1991; Ying et al., 2001), promoters derived from chlorella or their virus would be suitable in the chlorella expression system. It has been shown that a promoter isolated from the typical chlorella virus, PBCV-1, could work in plants (Amitava et al., 1994). It is believed that PBCV-1 virus uses host transcription machinery to make its transcripts because it does not encode its own RNA polymerase (Schuster et al., 1986a; Van Etten et al., 1988). However, the virus encodes a number of transcriptional factors in its $340 \mathrm{~kb}$ genome (Ann et al., 1990). It has been known that a $33 k D a$ gene was the most abundant in vitro translation product and the promoter can work as a strong promoter in a eukaryotic expression system (Graves and Meints, 1992). Therefore, the promoter region of the $33 \mathrm{kDa}$ peptide was obtained from YK-1 isolate, a chlorella virus isolated in Korea, and was integrated into the design for a chlorella transformation system.

The sequence analysis of the cloned $33 k D a$ gene promoter showed $96 \%$ nucleotide sequence homology to that of PBCV-1 (Fig. 3). Despite the high sequence homology between them, there were two deletions in the promoter region of YK-1 (Fig. 3). In one of the deletions, 3 repeats of the AAAC sequence that appears 15 times in PBCV-1 $33 k D a$ gene promoter are missing. This sequence has been suggested to have an important role in transcription (Graves and Meints, 1992). This suggestion has been supported by the finding that the promoter of the PBCV-1 $33 \mathrm{kDa}$ gene contains no obvious eukaryotic promoter elements. Therefore, it is necessary to investigate the importance of the repeated sequence and the effect of three deletions in YK-1 isolate on the promoter activity.

The other sequence introduced into the transformation vector was the 3' UTR of the 33kDa gene for the transcription termination. The formerly developed chlorella trans- formation vector pCTV does not have any sequence for the termination of transcription of the target gene (Kim et al., 2002). Therefore, two transcripts, one transcript containing the target gene started from CaMV $35 \mathrm{~S}$ promoter and another transcript for $S h$ ble gene that initiates from the $\mathrm{RBC} 2 \mathrm{~S}$ promoter are expected to be co-terminated at the potato protease inhibitor gene termination signal, $\operatorname{Ter}(\mathrm{pl})$, that is located after the Sh ble gene. In order to separate the target gene and Sh ble gene, the 3' UTR of the 33kDa gene of YK1 isolate was cloned between the EPO gene and the RBC2S promoter. Sequence analysis of the cloned 3' UTR from the $33 k D a$ gene of YK-1 isolate showed $88 \%$ homology to that of PBCV-1. The TTTTTTT sequence that has been suggested to function as a transcription termination sequence of vaccinia virus was also found in the PBCV-1. However, it was not found in YK-1. Instead, the TATATTT sequence was present at this location. Other sequences of interest found in this region are the TGATTGAA motif that is repeated twice in both PBCV-1 and YK-1 and the ATGTAAAAA motif that is repeated twice in the PBCV-1 but only once in YK-1. However, the importance of these motifs in transcription termination is not yet known.

Stable integration of introduced DNA into chromosomal DNA is a prerequisite for the stable expression of an introduced target gene. The presence of introduced DNA was confirmed in two ways. First, the transformed chlorella was cultured in the presence of the selective antibiotic, phleomycin. Cell growth was detected only from chlorella cells transformed with three constructed transformation vectors and was not detected from non-transformed cells. This indicated the presence and the expression of the introduced Sh ble gene. The integration of introduced DNA was further confirmed by PCR amplification of EPO gene from genomic DNAs isolated from the transformed cells. PCR product with expected size was detected from only the transformants. Furthermore, the PCR products specifically hybridized to EPO specific probes in southern blot analysis. Collectively, these data suggest that DNA was stably integrated into the chlorella chromosomal DNA and that the Sh ble gene was functionally expressed in the transformed cell.

The activity of the $33 \mathrm{kDa}$ gene promoter and the 3' UTR on the transcription and target gene expression was tested by ELISA assay. There was no significant difference in the expression levels of EPO protein in chlorella cells transformed with either of three transformation vectors. The CaMV 35S promoter is a strong promoter and most commonly used in plant transformation (Gmunder and Kohli, 1989; Pobjecky et al., 1990). Our results indicate that the promoters from the chlorella virus are comparable to the CaMV 35S promoter and other promoters from this virus may be used in chlorella transformation. However, the 
presence of the 3' UTR did not affect the expression level. This might be due to the small size of the Sh ble gene down stream of the EPO gene. The other possibility is that the $3^{\prime}$ UTR did not work as a transcription termination signal in this system. This possibility needs to be confirmed by an additional method such as northern blot analysis of mRNA produced in the transformed chlorella cell. We are currently trying to find chlorella virus promoters that are stronger than the promoters that were identified and described in this research.

\section{Acknowledgment}

This work was supported by Pukyong National University Research Abroad Fund in 2001.

\section{References}

Amitava, M., Dan, W. H. and Nancy, J. R. 1994. A Chlorella virus gene promoter functions as a strong promoter both in plants and bacteria. Biochem. Bioph. Res. Comm. 204:187-194.

Anne, M. S., Michael, G., Kenneth, K., Marcia, Z., Jhon, B., Daniel, G. and Russel, H. M. 1990. Transcription and sequence studies of a 4.3-kbp fragment from a ds-DNA eukaryotic algal virus. Virology 176:515-523.

Cho, H. H., Park, H. H., Kim, J. O. and Choi, T. J. 2002. Isolation and Characterization of Chlorella Viruses from Freshwater Sources in Korea. Mol. Cells 14:168-176.

Dawson, H. N., Burlingame, R. and Cannons, A. C. 1997. Stable transformation of Chlorella: Rescue of nitrate reductase-deficient mutants with the nitrate reductase gene. Curr. Microbiol. 35:356-362.

Dunahay, T. G. 1993. Transformation of Chlamydomonas reinhardtii with silicon carbide whiskers. Biotechniques 15:452-460.

Eric, D. and Caroline, E. 1991. Influence of storage conditions on the activity of recombinant hirudin. Thromb Res. 61:87-89.

Gmunder, H. and Kohli, J. 1989. Cauliflower mosaic virus promoters direct efficient expression of a bacterial G418 resistance gene in Schizosaccharomyces pombe. Mol. Gen. Genet. 220:95-101.

Graves, M. V. 1992. Characterization of the gene encoding the most abundant in vitro translation product from virus-infected chlorella-like algae. Gene 149-155.

Graves, M. V. and Meints, R. H. 1992. Characterization of the major capsid protein and cloning of its gene from algal virus PBCV-1. Virology 188:198-207.

Graves, M. V., Bernadt, C. T., Ronald, C. and Van Etten, J. L. 2001. Molecular and genetic evidence for a virus-encoded glycosyltransferase involded in protein glycosylation. Virology 285:332-345.

Graves, M. V., Burbank, D. E., Roth, R., Heuser, J., DeAngelis, P. L. and Van Etten, J. L. 1999. Hyaluronan synthesis in virus PBCV-1-infected chlorella-like green algae. Virology 257:1523.

Gerald, F. K., Yu, L., Zhiqang, L., Masakazu, F., Daniel, L. R. and
Van Etten, J. L. 1996. Analysis of 76kb of the chlorella virus PBCV-1 330-kb genome: Map positions 182 to 258. Virology 223:303-317.

Hasnain, S. E., Manavathu, E. K. and Leung, W. C. 1985. DNAmediated transformation of Chlamydomonas reinhardi cells: use of aminoglycoside 3'-phosphotransferase as a selectable marker. Mol. Cell. Biol. 5:3647-3650.

Jarvis, E. E. and Brown, L. M. 1991. Transient expression of firefly luciferase in protoplasts of the green alga Chlorella ellipsoidea. Curr. Genet. 19:317-321.

Kim, D. H., Kim Y. T., Cho, J. J. Bae, J. H., Hur, S. B. Hwang, I. and Choi, T. J. 2002. Stable integration and functional expression of flounder growth hormone gene in transformed microalga, Chlorella ellipsoidea. Mar. Biotechnol. 4:63-73.

Lavrukhin, O. V., Fortune, J. M. Wood, T. G., Burbank, D. E., Van Etten, J. L., Osheroff, N. and Lloyd, R. S. 2000. Topoisomerase II from chlorella virus PBCV-1. Characterization of the smallest known type II topoisomerase. J. Biol. Chem. 275:6915-6921.

Pobjecky, N., Rosenberg, G. H., Dinter-Gottlieb, G. and Kaufer, N. F. 1990. Expression of the beta-glucuronidase gene under the control of the CaMV 35s promoter in Schizosaccharomyces pombe. Mol. Gen. Genet. 220:314-316.

Schuster, A. M., Graves, M., Korth, K., Ziegelbein, M., Brumbaugh, J., Grone, D. and Meints, R. H. 1990. Transcription and sequence studies of a $4.3-\mathrm{kbp}$ fragment from a ds-DNA eukaryotic algal virus. Virology 176:515-523.

Schuster, A. M., Girton, L., Burbank, D. E. and Van Etten, J. L. 1986a. Infection of a Chlorella-like alga with the vinus PBCV1: transcriptional studies. Virology 148:181-189.

Schuren, F. H. and Wessels, J. G. 1994. Highly-efficient transformation of the homobasidiomycete Schizophyllum commune to phleomycin resistance. Curr Genet. 26:179-183.

Sorokin, C. and Krauss, R. W. 1958. The effect of light intensity on the growth rate of green algae. Plant Physiol. 33:109-113.

Sun, L., Adams, B., Gurnon, J. R., Ye, Y. and Van Etten, J. L. 1999. Characterization of two chitinase genes and one chitosanase gene encoded by chlorella virus PBCV-1. Virology 263: 376-387.

Van Etten, J. L., Schuster, A. M. and Meints, R. H. 1988. Viruses of eukaryotic Chlorella-like algae. In "Viruses of Fungi and Simple Eukaryotes" (Koltin, Y. and Leibowits, M. J. Eds.), Dekker, New York.

Xia, Y. and J. L. Van Etten. 1986. DNA methyltransferase induced by PBCV-1 virus infection of a Chlorella-like green alga. Mol. Cell. Biol. 6:1440-1445.

Ying, C., Yiqin, W., Yongru, S., Liming, Z. and Wenbin, L. 2001. Highly efficient expression of rabbit neutrophil peptide-1 gene in Chlorella ellipsoidea cells. Curr Genet. 39:65-370.

Yuen, L. and Moss, B. 1987. Oligonucleotide sequence signaling transcriptional termination of vaccinia virus early genes. Proc. Natl. Acad. Sci. USA 84:6417-6421.

Zang, B., Tao, T., Wilson, G. G. and Blumenthal, R. M. 1998. The MAluI DNA-(cytosine C5)-methyltransferase has an unusually large, partially dispensable, variable region. Nucleic Acids Res. 21:905-911. 